\title{
IMPLANTAÇÃO DE UMA PLATAFORMA MARÍTIMA CROSS DOCKING INTERCONTINENTAL
}

\author{
Maria Vitória Campos da Silva (IFRN) mariavitoriacampoa@gmail.com \\ Isaac Manoel Gregório Paulo Primo (IFRN) isaacgregorio14@hotmail.com \\ Lucas Medeiros de Araújo (IFRN) lucasmdearaujohotmail.com \\ João Batista Pereira da Silva (IFRN) Joaobp.Silva0003@gmail.com \\ Paulo Vitor Dias Palhares (IFRN) pvpalhares.pp@gmail.com
}

\begin{abstract}
Resumo
Como um dos modais mais utilizados para fazer conexões entre os países, o modal aquaviário transporta mercadorias em grandes quantidades e a longas distâncias com baixos custos. Devido a essas características, é empregado para proporcionar interações comerciais entre países que são detentores de recursos naturais (minérios, petróleo, gás natural, terras cultiváveis para agricultura, pastagens para a pecuária, etc.), estes por sua vez exportam para países que não possuem matéria-prima disponível, gerando assim o comercio entre ambos. Com o intuito de otimizar os processos logísticos realizados pelos navios, este estudo teve em vista a implementação de uma plataforma marítima Cross Docking, sendo assim, a distribuição de insumos ocorreria de maneira eficaz.

Palavras-chave: Modal Aquaviário, Processos Logísticos, Plataforma Marítima Cross Docking

\section{Introdução}

O transporte marítimo é um dos modais mais utilizados no mundo, onde transcorrem em oceanos e mares por meio de barcos, navios etc. Cerca de $90 \%$ das mercadorias internacionais são transportadas pelo transporte marítimo por possuir benefícios como alta capacidade de carga e baixo custo para transporte, sendo importante para o comércio global.

O Oceano Atlântico é o segundo maior do mundo, possuindo conexões com diversos países, inclusive o Brasil e essa condição possibilita um bom uso do mar para a movimentação de mercadorias, entretanto ainda se observam gastos desnecessários em relação ao transporte. Muitos dos navios mercantes não retornam ao país de origem com toda a sua capacidade de carga. Segundo a Marinha do Brasil (2019) foi escoado mais de 95\% do comercio exterior brasileiro por meio das rotas marítimas, sendo reflexo da grande extensão litoral do país que conta com $7.367 \mathrm{Km}$ e das condições climáticas que favorecem o modal aquaviário. Nesse contexto, destaca-se o Rio Grande do Norte (RN), estado do nordeste brasileiro com um litoral
\end{abstract}


de $410 \mathrm{~km}$ o qual possui a maior entrada para o Atlântico, tornando-se oficialmente o estado mais próximo a Europa e a África.

Esse bom posicionamento geográfico permite a realização de um estudo no entorno da área do mar do RN cujo objetivo teria em vista à implementação de uma plataforma marítima Cross Docking para otimização dos processos logísticos.

Com a crescente demanda de consumidores se faz necessária a busca por aprimoramentos logísticos justificando que o estudo ocasionaria em uma melhor experiência para o consumidor e menos custos aos empreendedores. A realização desse projeto acarretaria novos postos de trabalho, além de contribuir para a valorização dos profissionais de engenharia e logística na região.

\section{Referencial Teórico}

\section{1 . Logística}

A Logística é uma área que vem sendo estudada há anos, agregando várias definições de diversos autores.

De acordo com Novaes em uma de suas citações:

"O longo caminho que se estende desde as fontes de matéria-prima, passando pelas fábricas dos componentes, pela manufatura do produto, pelos distribuidores e chegando finalmente ao consumidor constitui a cadeia de suprimentos. A logística é responsável por administrar e coordenar os recursos utilizados para a movimentação de equipamentos e materiais das empresas, além de coordenar a compra, armazenagem, transporte e

\subsection{Armazém} distribuição." (Novaes, Antônio G. 2007, p. 38)

Armazém é o local construído para estocar os produtos, o armazém pode possuir diversos layouts(formas), dependendo da necessidade, quantidade e tipos de produto. Investimentos em armazéns de qualidade é importante para evitar avaria dos produtos ou até mesmo problemas externos como roubos. Mas há outras definições de autores, tal como:

"É tida como uma importante função para atender com efetividade a gestão da cadeia de suprimento. Sua importância reside no fato de ser um sistema de abastecimento em relação ao fluxo logístico, que serve de base para sua uniformidade e continuidade, assegurando um adequado nível de serviço e agregando valor ao produto" ( Gasnier \& Banzato, 2001) 
Dias (1996) também afirmou sua tese sobre a eficiência da armazenagem estar ligada a duas naturezas (material movimentado e armazenado) e se houvesse uma boa administração no almoxarifado iria trazer um aproveitamento melhor da matéria-prima e na movimentação evitaria a perda de peças por batidas e impactos e consequentemente haveria uma economia nos custos logísticos de movimentação.

\subsection{Estoque}

O estoque são os produtos armazenados, mas essa explicação ainda não é o suficiente para descrever essa atividade, então alguns autores desenvolveram definições, como:

"O estoque e definido como acumulação de recursos materiais em um sistema de transformação. Algumas vezes estoque também e usado para descrever qualquer recurso armazenado. Não importa o que está sendo armazenado como estoque, ou onde ele está posicionado na operação, ele existira porque existe uma diferença de ritmo ou de taxa entre fornecimento e demanda." (Slack e et al ,1997)

Assaf Neto (2005) complementa a necessidade de um estoque bem administrado quando disse que "por demandarem vultosos volumes de recursos (imobilizados) aplicados em itens de baixa liquidez, devem as empresas promover rápida rotação em seus estoques como forma de elevar sua rentabilidade e contribuir para manutenção de sua liquidez”.

Com essa explicação já se percebe a importância da temática, o estoque como sendo parte do capital da empresa é indispensável o uso de uma boa gestão de estoque, para Vendrame (2008) a gestão de estoque é um conjunto de questionamentos que o indivíduo deve realizar para tomar a melhor decisão.

\subsection{Transporte}

Os modais de transporte são fundamentais para as operações Logísticas, quando bem gerenciados permitem uma rápida movimentação dos produtos dentro da cadeia de suprimentos, a velocidade e flexibilidade com que uma empresa administra esse recurso pode influenciar diretamente no relacionamento com o cliente, tendo em vista que em um mundo globalizado o tempo nunca foi tão decisivo.

Sabendo disso cada vez mais as empresas procuram fazer investimentos nessa área. Nazário (apud Fleury, 2000, p. 126) declara que o transporte representa, em média, cerca de $60 \%$ dos custos Logísticos, variando entre $4 \%$ e $25 \%$ do faturamento bruto. Lima (2006) acrescenta, os custos de transportes Logísticos no Brasil equivalem cerca de 7,5 do PIB (Produto Interno Bruto). 


\subsection{Modal Aquaviário}

O modal aquaviário possui 3 modos de navegação: o fluvial, o lacustre e o marítimo. O Brasil tem a capacidade de explorar com eficácia alguns deles dado o fato do seu tamanho continental, só o Rio São Francisco possui aproximadamente 2.000 km navegáveis e o país tem em sua totalidade um litoral de $9.198 \mathrm{~km}$, se bem explorado teria um retorno significativo para a economia nacional.

É importante mencionar que existem 3 categorias de transporte marítimo, segundo Mário Silva Florentino (Gestão de Custos no Transporte Marítimo de Cargas no Brasil, 2010, p. 25) são:

- Cabotagem: navegação realizada entre portos ou pontos do território brasileiro, utilizando a via marítima ou entre esta e as vias navegáveis interiores.

- Navegação interior: realizada em hidrovias interiores ou lagos, em percurso nacional ou internacional.

- Navegação de Longo Curso: realizada entre portos de dois continentes.

Segundo as pesquisas da ANTAQ (Agência Nacional de Transporte Aquaviário), no ano de 2018, na movimentação de longo curso, foram transportadas 823 milhões de toneladas de carga, representando um crescimento de $32 \%$ no período de 2010/2018; na cabotagem foi movimentado 229 milhões de toneladas, tendo um crescimento de $26 \%$ no período de 2010/2018; já na navegação interior foram 61 milhões de toneladas, apresentando um crescimento de 61 milhões de toneladas, registrando $105 \%$ de crescimento em relação ao mesmo período. Lembrando que no ano de 2007 a navegação de longo curso foi responsável por $90 \%$ do comércio internacional brasileiro.

\subsection{Plataforma logística}

Plataforma logística é uma base que integra modais de transporte, com predisposição para possibilitar a intermodalidade. Podendo ser também analisado como terminais intermodais, onde o transbordo de mercadorias entre os modais é estendido.

Boudoin (1996) expressou sua opinião da seguinte maneira:

"Uma plataforma logística é o local de reunião de tudo o que diz respeito à eficiência logística. Acolhe zonas logísticas de empreendimentos e infra-estruturas de transporte, importantes por sua dinamização na economia, melhorando a competitividade das empresas, criando 
empregos e viabilizando as atividades logísticas, pois há uma crescente necessidade das instalações se organizarem para atender os usuários clientes (industriais e distribuidores). A armazenagem e outras instalações utilizadas nas atividades de transportes marcam o espaço. Assim, torna-se útil efetuar o agrupamento dos usuários clientes" (Boudoin, 1996)

Segundo Duarte (1999) apud Boudoin (1996), uma plataforma logística é composta de três subzonas com funções especiais:

-Subzona de serviços gerais: áreas que englobam recepção, informação, acomodação e alimentação, bancos, agência de viagens de estacionamento, abastecimento e reparos, serviços de alfândega, administração e comunicação.

-Subzona de transportes: que agrupa infra-estruturas de grandes eixos de transportes. É muito importante que a plataforma seja multimodal e possua terminais multimodais, integrando transportes rodoviários, ferroviários, marítimos e aéreos.

-Subzona destinada aos operadores logísticos: dando condições de prestar serviços de fretamento, corretagem, assessoria comercial e aduaneira, aluguel de equipamentos, armazenagem, transporte e distribuição.

Figura 1: Desenho funcional de uma plataforma logística

\section{DESENHO FUNCIONAL DE UMA PLATAFORMA} LOGÍSTICA

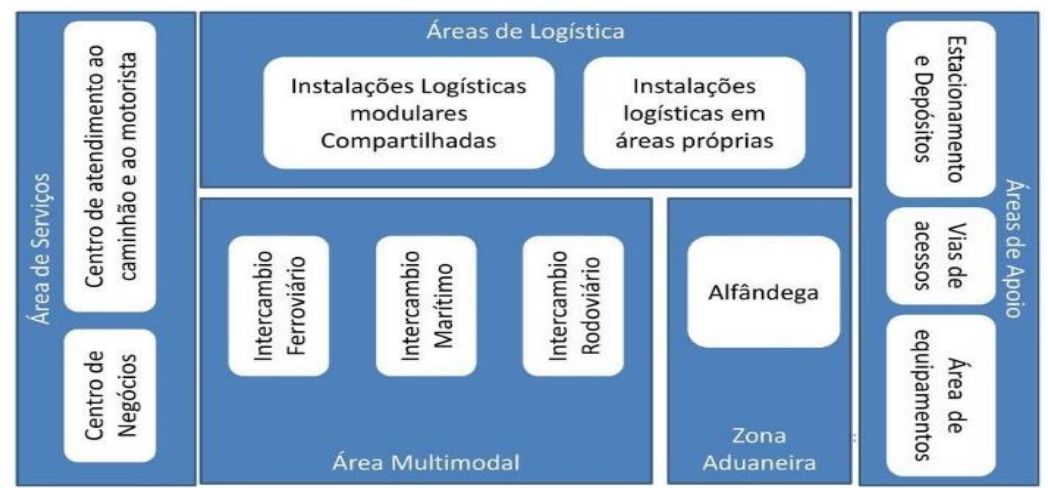

Fonte: ( Google)

\subsection{Tipos de Plataforma logística}

Conforme Dias (2005) cita, de acordo com a Associação Europeia de Plataformas Logísticas (Europlatforms), existem infraestruturas deste tipo com um só modo de transporte, unimodais, ou com mais do que um modo, multimodais. Quanto às Plataformas Logísticas Multimodais, Dias (2005) cita de acordo com os conceitos da Europlatforms, que são 
conhecidas nesta tipologia as Zonas de Atividades Logísticas Portuárias (ZAL), os Centros de Carga Aérea e os Portos Secos. Já Bacovis (2006) classifica as plataformas unimodais em: Centros ou Terminais Rodoviários, os Centros de Distribuição Urbana, os Parques de Distribuição e os Centros de Transportes.

\subsection{Cross-Docking}

O Cross Docking é um processo em que os automóveis se encontram em um ponto específico e distribuem suas mercadorias e retornam ao seu destino, isso requer uma alta organização e roteamento. (Fábio Barroso em: A OPERAÇÃO DE CROSS-DOCKING).

Outros autores exemplificam o Cross-Docking como um Centro de Distribuição em que os produtos são imediatamente despachados para transporte, semelhante a um rápido armazém, dessa forma a carga transportada é transferida do ponto de recebimento para o ponto de entrega com um tempo de estoque reduzido. EAN International (2000); (Patrícia Fernandes de Oliveira e Nélio Domingues Pizzolato em: A EFICIÊNCIA DA DISTRIBUIÇÃO ATRAVÉS DA PRÁTICA DO CROSS DOCKING)

Figura 2: Processo de um Cross Docking

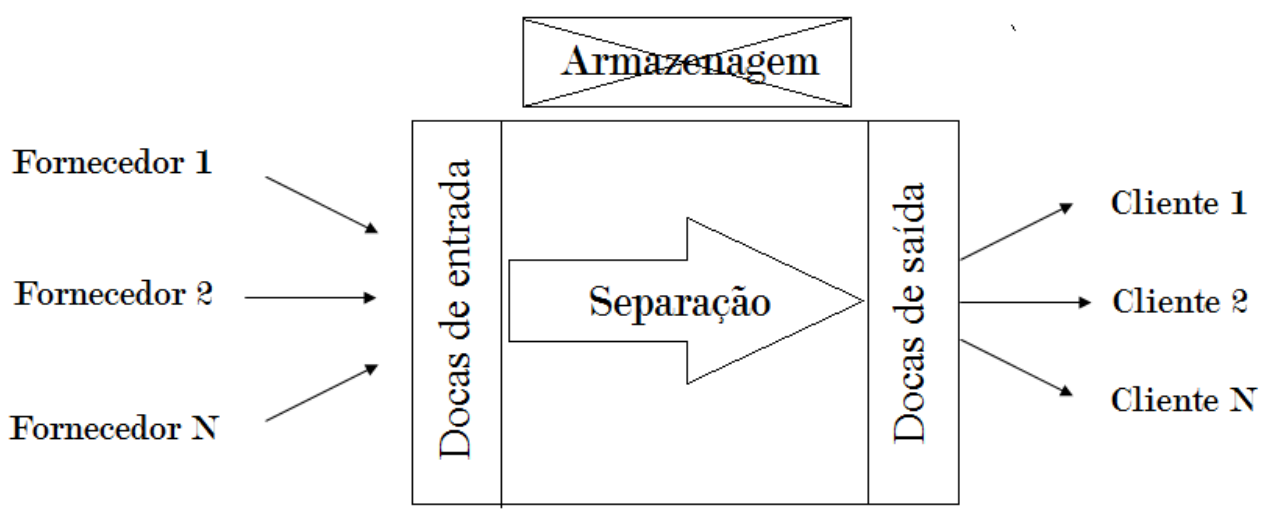

(Fonte: Pires 2004)

Recebendo mercadorias provenientes de vários fornecedores, as mercadorias são reorganizadas de forma que combine as mercadorias e separe pedidos de clientes comuns. De acordo com Pires (2004), para que o procedimento obtenha êxito é necessário que haja integração e sincronização entre os programas de expedição e recebimento de cargas.

\section{Estudo de caso}

O presente estudo de caso teve como parâmetro dados bibliográficos e governamentais sobre a atual situação do modal aquaviário e o comércio marítimo internacional. Comentamos sobre plataformas logísticas as suas vantagens e o impacto da sua utilização, demonstramos o 
processo Cross Docking em suas mais diversas aplicações. Utilizamos recentes estudos de estoque e armazém para agregar conteúdo na pesquisa.

\section{Metodologia da Pesquisa}

Esse projeto consiste em um estudo que tem por objetivo realizar a implementação de uma plataforma marítima Cross Docking no entorno do mar do RN, utilizando o estudo de conhecidos autores como base. A pesquisa deu início no mês de novembro/2018 sendo estudado a partir de pesquisa de livros e artigos publicados de autores.

Para uma melhor fundamentação, esse trabalho foi dividido em etapa I- pesquisas em livros sobre plataformas logísticas e armazenagem; etapa II- pesquisas em artigos já publicados sobre Cross Docking e plataformas marítimas e sobre dados do governo; etapa III- separar as opiniões mais recentes das mais antigas para um bom entendimento do processo; etapa IV- a partir do estudo sobre o conteúdo desenvolver uma boa estruturação e futura aplicação da pesquisa.

Para melhor entendimento sobre o processo feito no desenvolvimento da pesquisa foi resumida em passos.

Passo 1- Buscar em livros sobre o tema e desenvolver uma cadeia de pensamentos baseados nos pensamentos do autor.

Passo 2- A partir de artigos traçar uma linha entre a plataforma Cross Docking e o local onde seria aplicada sua base.

Passo 3- pesquisas sobre dados fornecidos pelo governo e critérios para conseguir realizar um projeto como esse.

Passo 4- Ao ler sobre as opiniões e conceito dos autores, separar por ordem cronológica afim de perceber quais mudanças e aperfeiçoamentos foram desenvolvidos ao longo do tempo.

Passo 5- A partir dos dados coletados, desenvolver uma linha de raciocino que vai desde o estudo de conceitos para o planejamento de espaço e de parada de mercadorias até a implantação da plataforma marítima Cross Docking.

\section{Resultados Esperados}

Com base em pesquisas feitas, o projeto da plataforma logística com atividades Cross Docking em alto mar, terá um impacto positivo entre empreendedores que buscam uma melhor rota de serviço com mais economia e menor percentual de danos aos seus produtos no destino final. 
O processo daria início ainda antes do embarque onde a mercadoria é escolhida e colocada em contêineres com sua identificação e a do navio na qual é transferida a mercadoria na plataforma, facilitando assim ter uma melhor noção da localização da embarcação no mar.

A plataforma adotaria o sistema de carga fracionada e consolidada. Esse processo se adequaria de acordo com a demanda, visando proporcionar as melhores condições de aproveitamento de tempo, espaço e transporte. No sistema de carga fracionada será como um único navio com carga $\mathrm{N}$ chegando à plataforma e transferindo a mercadoria para uma quantidade $\mathrm{X}$ de embarcações na qual seriam levadas a diferentes portos entre os continentes citados, já no sistema de carga consolidado, uma quantidade $\mathrm{Y}$ de embarcações chegariam à plataforma deslocando a mercadoria para um único navio.

No tocante à quantidade de docas em nossa plataforma, seriam distribuídas entre $52 \mathrm{e}$ 60 desses terminais onde a embarcação é abrigada para ser inspecionada e reparada enquanto a mercadoria é descarregada e separada no armazém para ser transportada à outra embarcação que levará ao porto para ser distribuída nos destinos comerciais.

Figura 3: Fluxograma espelhado nessa pesquisa
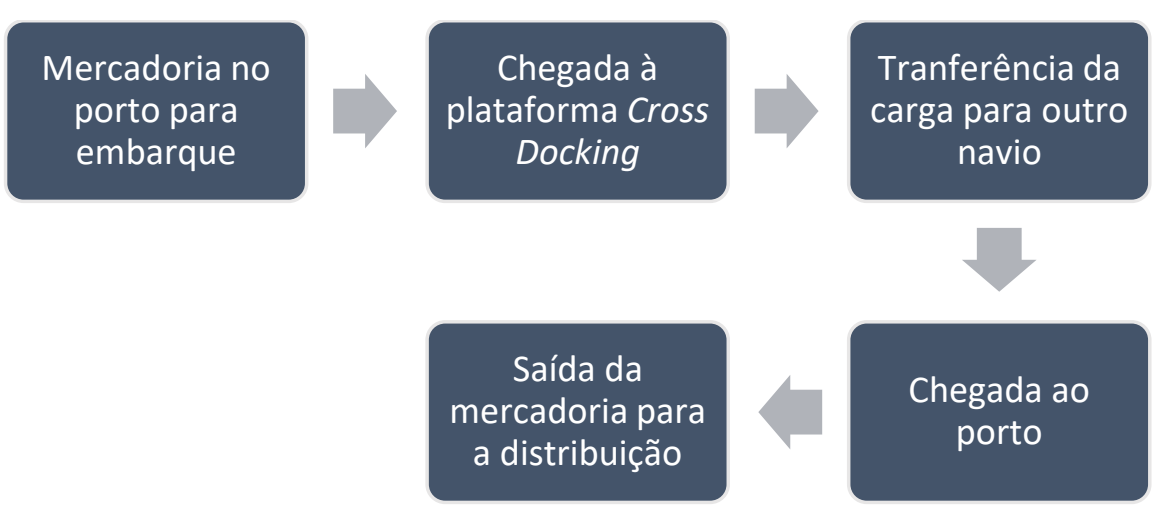

(Fonte: Elaborado pelos autores)

No referente à armazenagem da mercadoria recém chegada na plataforma, teriam locais amplos para o fluxo das mercadorias e revisões das mesmas e em casos emergenciais tal como: possíveis reparos em contêineres danificados visando não ter a perca de mercadorias.

Para cada setor do armazém terão $\mathrm{N}$ funcionários distribuídos para limpeza, manutenção, movimentação das mercadorias dentro do estoque, climatização e segurança.

A plataforma logística Cross Docking deve localizada estrategicamente entre os continentes: Americano, Africano e Europeu, beneficiando assim os países que dependem do comércio marítimo. 
Figura 4: Imagem base de posicionamento da plataforma Cross Docking com localização via satélite

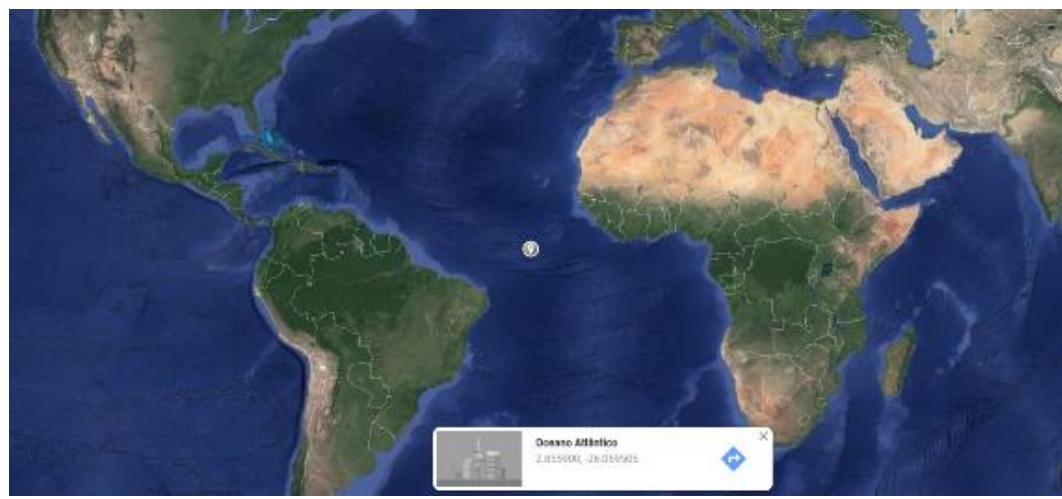

(Fonte: google maps)

$\mathrm{O}$ encurtamento das rotas comerciais deve aumentar o fluxo de mercadorias entre os países permitindo o retorno constante à plataforma. Como resultado seria notável a redução de avaria das mercadorias transportadas. O planejamento possibilita que o transporte se desloque com sua total capacidade e retorne da mesma forma, não havendo desperdício de combustível ou espaço no armazém.

Figura 5: Localização via satélite do dia 23/02/2020 das rotas das embarcações em comércio marítimo

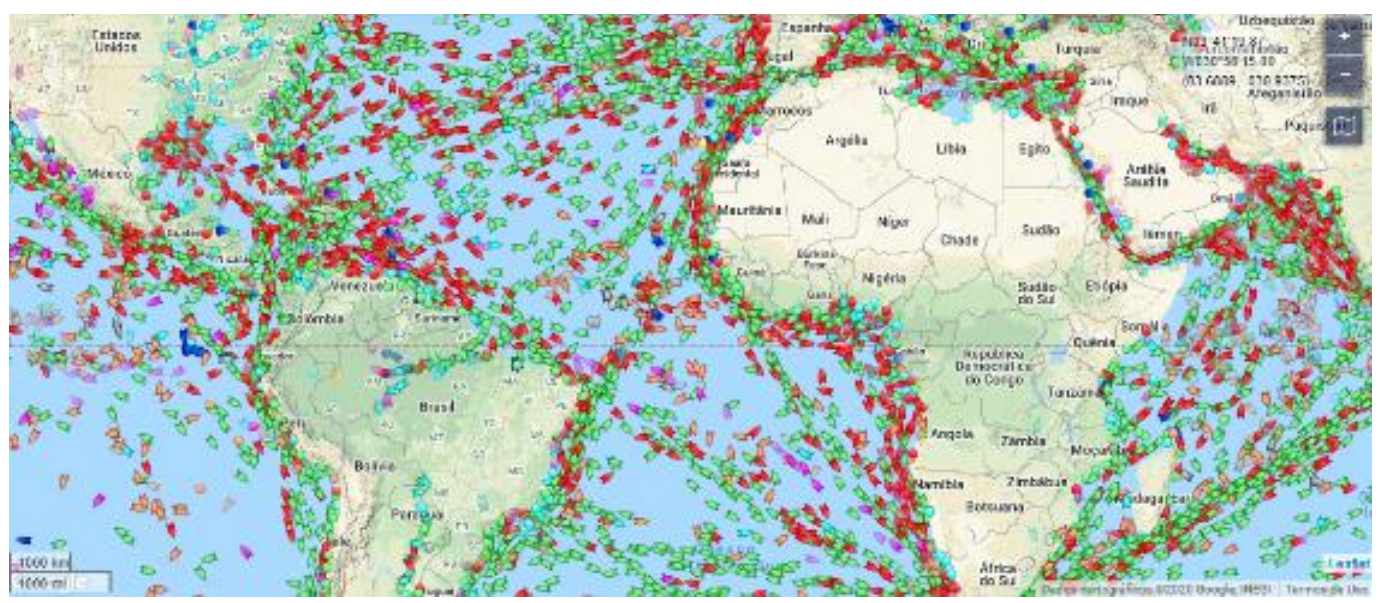

(Fonte: Marinne Traffic)

\section{Conclusão}

O objetivo desse artigo é a pesquisa e análise para uma possível implementação de uma plataforma marítima Cross Docking para otimização dos processos logísticos.

A busca por aprimoramentos logísticos justifica esse estudo para que seja obtido melhores e mais rápidas experiências paro o consumidor e menos custo aos empreendedores a partir do momento que reduziria a danificação de suas mercadorias. A realização desse projeto 
acarretaria novos postos de trabalho, além de contribuir para a valorização dos profissionais de engenharia e logística na região.

Portanto, se tornaria precisa a implantação de uma plataforma logística marítima afim de apresentar melhorias na logística do comércio de mercadorias entre o Brasil e os continentes Africano e Europeu.

\section{REFERÊNCIAS}

Dados fornecidos Pela Marinha do Brasil: https://www.marinha.mil.br/economiaazul/noticias/o-que-\%C3\%A9-amaz\%C3\%B4nia-azul-e-por-que-o-brasil-quer-se-tornarpot $\% \mathrm{C} 3 \%$ AAncia-militar-no-at1\%C3\%A2ntico

Dados sobre a movimentação portuária da ANTAQ: https://tinyurl.com/dadosANTAQ

Desenho funcional de uma plataforma logística: https://docplayer.com.br/2633446-Plataforma$\underline{\text { logistica-instrumento-importante-para-maior-eficiencia-logistica-dos-portos-brasileiros-o- }}$ caso-do-porto-de-santos.html

Fábio Barroso, A Operação de Cross Docking: https://tinyurl.com/crossdockingFabio

Figura de um processo Cross Docking : https://www.researchgate.net/figure/Figura-1-Transitpoint-Fonte-Pires-2004-As-instalacoes-cross-docking-recebem_fig1_265468436

Imagem da localização da plataforma Cross Docking:

https://www.google.com.br/maps/@6.2722521,-11.831224,12143132m/data=!3m1!1e3

$\underline{\mathrm{D}}$

Localização atual de embarcações: https://www.marinetraffic.com/pt/ais/home/centerx:19.8/centery:6.3/zoom:3

$\begin{array}{llll}\text { Materiais em } & \text { Unidade } & \text { Industrial }\end{array}$

http://ppga.com.br/mestrado/2002/pereira_filho_orlandino_roberto.pdf

Marcela Maria e Rafaella Machado, Gestão de Estoque: https://tinyurl.com/gestaoestoque 
Marcos Xavier apud Antônio Novaes, As Novas Formas Organizacionais do Setor Atacadista Distribuidor e seu Rebatimento na Logística Territorial Brasileira: https://tinyurl.com/antonionovaes

Maria Márcia, Estudo Comparativo das Plataformas Logísticas Europeias x Brasileiras, como Forma de Identificar um Modelo que Atenda as Empresas do PIM: https://tinyurl.com/estudoplataformalogistica

Mario Silva Florentino, Gestão de Custos no Transporte Marítimo de Cargas no Brasil: https://tinyurl.com/Gest-odecustos

Orlandino Roberto Pereira Filho, Gerenciamento Logístico do Fluxo de Informações e Materiais em Unidade Industrial Aeronáutica:

http://ppga.com.br/mestrado/2002/pereira_filho_orlandino_roberto.pdf

Patrícia Fernandez e Nélio Domingues, A Eficiência da Distribuição Através da Prática do Cross Docking: https://tinyurl.com/eficienciadadistribuicao

Transporte Marítimo: https://tinyurl.com/transportemaritimoBrasil 